\title{
Strength of Wall-Slab Junction with New Form of Shear Reinforcement in a Laterally Loaded Tall Shear Wall Building
}

\author{
Abdul Aziz Ansari ${ }^{1}$, Muhammad Aslam Bhutto ${ }^{2}$, Nadeem-ul-Karim Bhatti ${ }^{3}$ and Rafique Ahmed Memon ${ }^{4}$ \\ 1. Department of Civil Engineering, Mehran University of Engineering and Technology, Khairpur Mirs 66020, Pakistan \\ 2. School of Built Environment, Heriot-Watt University Edinburgh, Edinburgh EH14 4AS, United Kingdom \\ 3. Department of Civil Engineering, Quaid-e-Awam University College of Engineering Science and Technology, Larkano 77150, \\ Pakistan \\ 4. Gawader Sea port Authority, Gawader Sea Port, Gawader 91200, Pakistan
}

\begin{abstract}
Very high concentration of flexural, shear and torsional stresses occurs at the wall-slab junctions in a laterally loaded tall building consisting of planar walls and coupling slabs. Due to this concentration of stresses and their interaction, there are great chances of failure to occur at the junction. Also the flexural stresses are not uniformly distributed and have the highest intensity near the periphery of inner walls but are reduced drastically as we move away from the wall-slab junction. Numerous attempts have been made to strengthen the wall-slab junction by using various types of shear reinforcement to ensure that shear failure should not occur. Various methods including fibre reinforcement consisting of twins of twisted steel couplets have already been used. This paper describes a new method of placing 2 inch wide flange I-sections at appropriate locations to improve the shear strength of the wall-slab junctions. Based on systematic research, a new procedure has also been developed to assess the strength of wall-slab junction using the new reinforcement method. Test results showed that a substantial increase, up to $57 \%$, in the shear strength of specimens was obtained by using the new method of shear reinforcement in a laterally loaded tall building.
\end{abstract}

Key words: Wall-slab junction, reinforcement, vertical steel bars, periphery of inner walls, I-section.

\section{Introduction}

The effect of wind and seismic loads becomes more pronounced with the increase in height of the building. In traditional system, the lateral stiffness to building is provided by extending rigid structural frames within fills serving the purpose of dividing the space.

In urban areas almost all over the world, the cost of land is rapidly increasing. The rapid increase in the cost of land is influencing a common practice of tall buildings. The tall buildings consist of load bearing RCC (reinforced cement concrete) cross-walls known as shear walls. The floor slab acts as a connecting

\footnotetext{
Corresponding author: Abdul Aziz Ansari, Dr., professor, research field: structural engineering. E-mail: dransari@quest.edu.pk.
}

medium between pair of the cross-walls and is known as coupling slab. In this structural form, these floor slabs also act as diaphragm and distribute the horizontal loads to the vertical shear walls. The height of storey can be kept up to a minimum level because no false ceilings are required to hide the beams. Perspective view of shear wall building is shown in Fig. 1.

In the design of tall buildings, special consideration has to be given for provision of the sufficient stability in all directions against the lateral forces due to wind, earthquake or blast. The lateral forces produce critical stresses in the structure, set up vibrations in the structure and cause lateral sway, which could reach a point of discomfort to the occupants. The shear walls resist the lateral loads on the structure by cantilever 


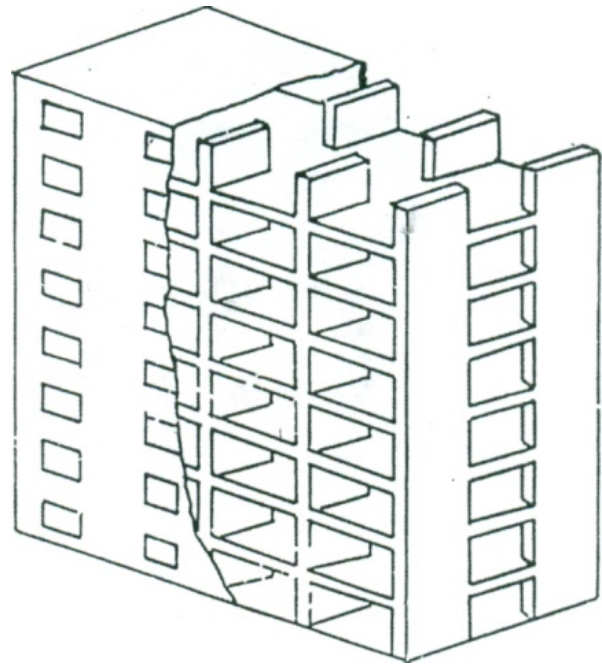

Fig. 1 Perspective view of a shear wall building.

bending action, which produces rotations of the wall cross-section. The free bending of a pair of shear walls is resisted by the floor slab, which is forced to rotate and bend out-of-plane where it is rigidly connected with the walls. Due to the large depth of shear wall, considerable differential shearing action is imposed on the coupling slabs, which develop transverse reaction to resist the wall deformations. As a result, a non-uniform shear with very high intensity is developed in the slab along the line of contraflexure (roughly centre line of corridor opening) and consequently unbalanced moments are induced along critical section of the slab with the highest concentrations at the inner face of wall, as shown in Fig. 2.

The non-uniform shear is ultimately transferred to the wall at the junction. The torsional stresses are also induced in the slab along the sides of walls. The interaction of all types of stresses makes the wall-slab junction vulnerable. Mahmood [1] proposed a method to estimate the strength of junction by adjusting the structural parameters and the material properties in such a way that the induced system of stresses should, under no circumstances, exceed the ultimate strength of junction. Attempts were made to increase the strength of the junction by various means $[2,3]$. Hossain [4] presented a paper on non-linear performance of slabs in coupled shear wall structures.

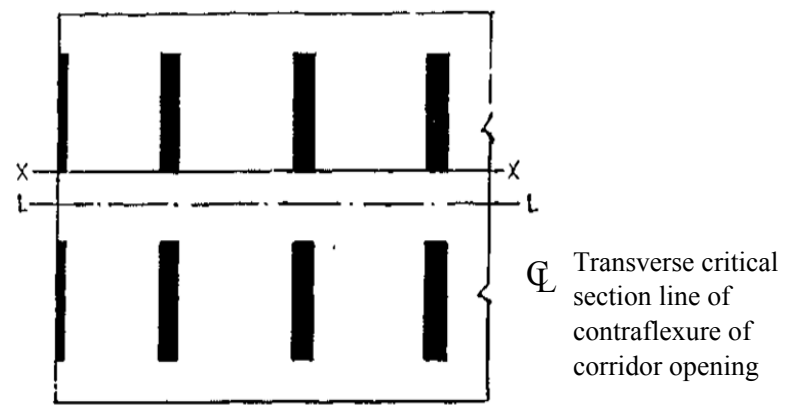

Fig. 2 Plan of a typical shear wall building showing the transverse critical section and line of contraflecture.

Memon and Narwani [5] presented the results of experimental behaviour of connecting beams in a laterally loaded shear wall building based on the results of first two models of a tall building tested by them. Rajkumar et al. [6] presented results of experimental behaviour of wall-slab joint in a laterally loaded shear wall building. Greeshma and Jaya [7] studied the response of shear wall, floor slab connection containing various types of shear reinforcement when subjected to gravity and lateral cyclic loading. The shear transfer coefficients for modeling the wall and slab joint, are adopted according to Wolanski [8]. However, there is a need to further investigate the problem and to strengthen the wall-slab junction by using some new forms of the reinforcement.

The aim of the present research work is to investigate the suitability and extent of increasing the strength of the wall-slab junction using a new form of vertical reinforcement consisting of the pieces of the 2 inch wide flange rolled steel I-section as shown in Fig. 3.

The I-sections are placed in the slab around wall periphery taking into consideration the location and the quantity of reinforcement as the major parameters. The purpose is to avoid punching shear failure of high rise buildings consisting of in-plane cross shear walls and coupling slabs subjected to lateral loads due to winds, etc..

The main objectives of the research are: (1) to improve the shear strength of wall-slab junction by providing new form of shear reinforcement in the slab 


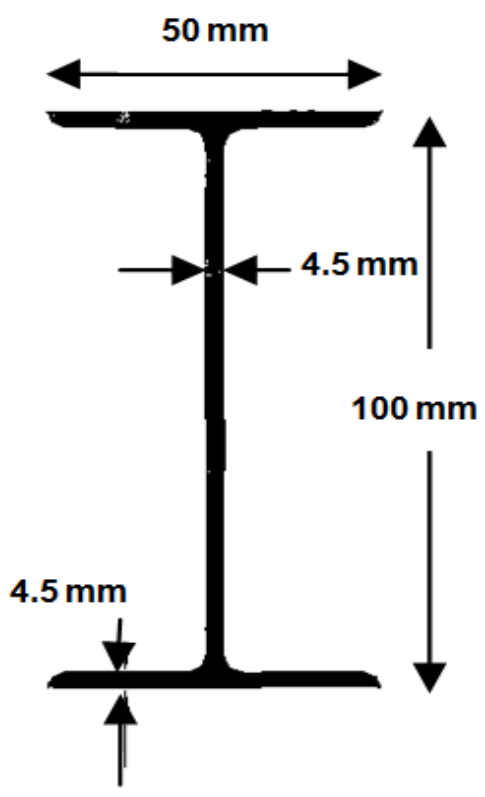

Fig. 3 Cross-sectional view of I-section.

around the wall periphery; (2) to avoid the use of vertical stirrups and the associated complications; (3) to find an economical and simpler form of shear reinforcement; (4) to prepare a proper design criteria for wall-slab junction with new type of reinforcement.

\section{Critical Conclusions}

Mahmood [1] proposed a method to estimate the strength of wall-slab junction but he did not attempt to strengthen it by using any form of reinforcement. Elnounu [9] used the wall configuration particularly

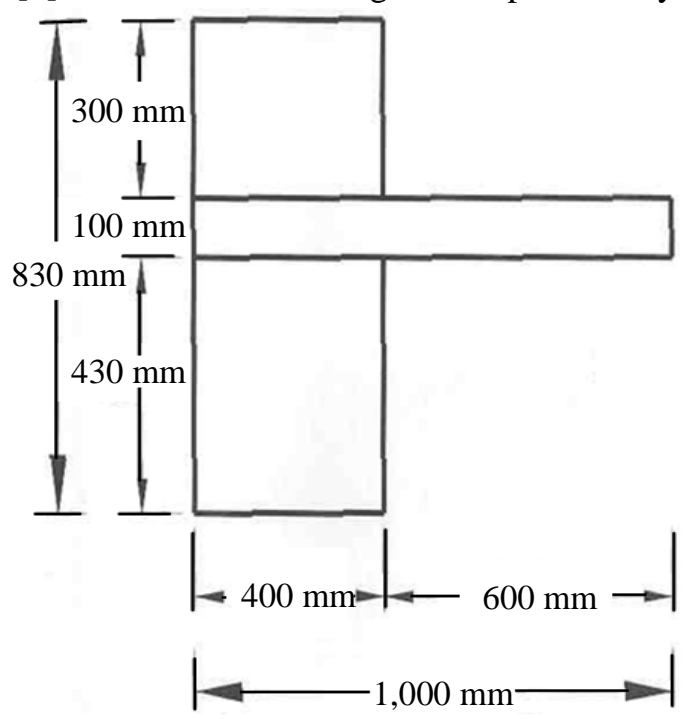

(a)
T-section, but surely construction of such wall is too expensive and might not at all be required from applied loads point of view. Bari [2] used vertical stirrups but it is too difficult to accommodate such type of reinforcement. Fibre reinforcement used by Noor [3] poses mixing problem and since it is randomly placed a sense of uncertainty prevails about its placement at appropriate location and appropriate direction to impart maximum strength against the junction failure. The idea of using rolled steel I-section pieces attempted by Dilger et al. [10] showed the results that are encouraging in the case of flat slab-column connection. The idea has therefore been used in the present research to find its suitability for the wall-slab junction in a laterally loaded shear wall building.

\section{Test Specimens}

Since it was deemed best to test specimens of real reinforced concrete of relatively large size so that the effect of size on the results could be minimized and let the behavior of specimens during the experimental study corresponds to that of actual structure as close as possible, the dimensions as shown in Fig. 4 were adopted for the specimens. For these specimens, the non-dimensional structural parametric ratios are as follows:

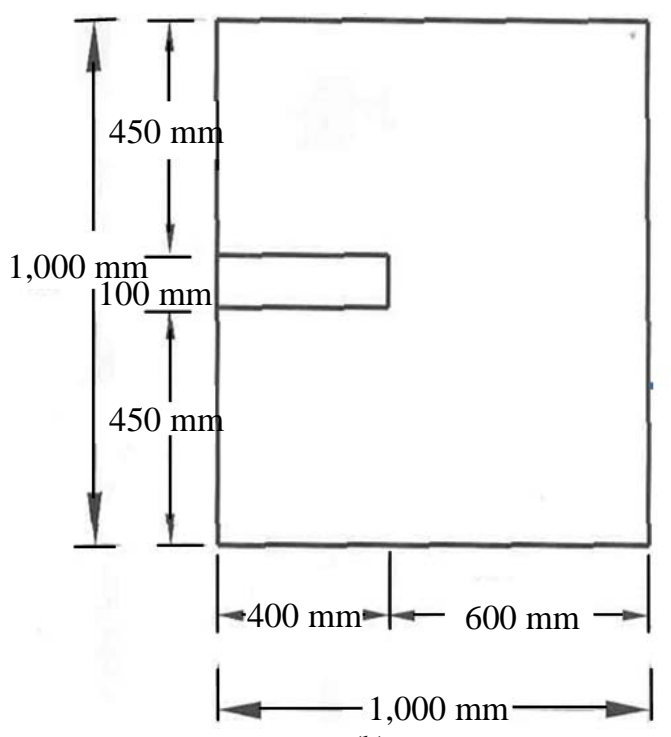

(b)

Fig. 4 Plan and elevation of the specimens showing dimension. 
- $L_{W} / X_{W}=0.6$;

- $Y_{W} / X_{W}=0.5$;

- $t_{W} / W_{W}=0.25$;

- $t_{W} / W_{W}=0.1$.

where:

$L_{W}$ is corridor opening width;

$X_{W}$ is over all width of the building;

$Y_{W}$ is bay width of connecting slab;

$t_{W}$ is thickness of wall;

$W_{W}$ is width of wall.

For the sake of economy, only one shear wall, a portion of slab cut along the central line of corridor opening, and the central lines of bay on both the sides of the wall were taken as specimen for this experimental study. Fig. 5 shows the isometric view of the specimen. The thickness of wall and slab and the width of bay, corridor opening and wall were selected in such a way that the non-dimensional structural parametric ratios remained within the practical range of such building. Although Mahmood [1] adopted the slab thickness of $150 \mathrm{~mm}$ for his main series (MT (main test)), depending upon several factors, the slab thickness for this experimental study was restricted to only $100 \mathrm{~mm}$. The factors considered in making these selections were the capacity of the supporting arrangement of specimens and other practical difficulties, which might have manifested themselves due to excessive rigid body rotations caused by relatively more loads, which would have been required because of enhanced flexural strength of the slab if thickness of slab was to be $150 \mathrm{~mm}$. However, the wall thickness, which was also $100 \mathrm{~mm}$ in this case as compared to $125 \mathrm{~mm}$ for MT series, was found to be enough, particularly from wall-slab junction strength point of view.

\section{Parameters of Study}

The most important parameter considered in the study was the quantity and location of the new form of shear reinforcement. The quantity of shear reinforcement ranges from $0 \%$ to $0.97 \%$ of critical section around the wall periphery while the location of steel varies from $0.5 d$ to $d$ (effective depth of the slab). A typical shape of $12 \mathrm{~mm}$ wide piece of I-section used as the new form of shear reinforcement is shown in Fig. 3. Table 1 gives the quantity, location and ratio of new form of the shear reinforcement.

\section{Flexural Design of Slab}

For the flexural design of slabs, methods originally proposed by Hago [11] for common slabs and later adopted by Muhammad [12] for coupling slabs was followed. This method makes use of moment triads obtained from elastic finite element analyses. With the help of Wood [13] and Armer [14] basic design equations, the areas of steel required at different points

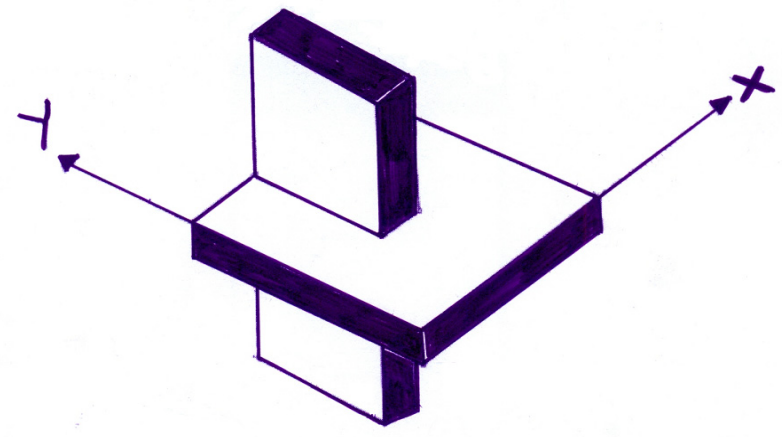

Fig. 5 Isometric view of the specimen.

Table 1 Locations, quantities and ratios of new form of shear reinforcement.

\begin{tabular}{lllll}
\hline Serial No. & Specimen No. & Location of I-section & No. of I-section & Percentage of I-section \\
\hline 1 & SWSJWNR-01 & - & - & 0.00 \\
2 & SWSJWNR-02 & $0.5 d$ & 11 & 0.74 \\
3 & SWSJWNR-03 & $0.5 d$ & 14 & 0.94 \\
4 & SWSJWNR-04 & $0.65 d$ & 14 & 0.88 \\
5 & SWSJWNR-05 & $d$ & 14 & 0.79 \\
6 & SWSJWNR-06 & $d$ & 17 & 0.79 \\
\hline
\end{tabular}

SWSJWNR means strength of wall-slab junction with new form of shear reinforcement. 
within the slab were calculated by following the recommendations of BSCP (British Standard Code of Practice) 8110 (1985) after removing all the factors of safety.

\section{Direct Ultimate Load Design Method}

Unlike a steel structure, the strength of a concrete structure can be tailored to match the required resistance at each point by providing just the required amount of steel reinforcement. This suggests a way of ultimate strength design of the reinforced concrete using elastic stress fields. This method is called direct ultimate load design method.

\section{Strength of Wall-Slab Junction}

Wall-slab junction is probably the most sensitive area of a shear wall structure. The failure of the junction will definitely be sudden, brittle, catastrophic and without impending warning. This must be avoided at all costs. In fact, this might prove to be the controlling factor when it comes to the design of a shear wall building. Mahmood [1] proposed a method to estimate the strength of connection for such junctions and location of critical shear perimeter around the wall periphery as shown in Fig. 6.

The method is simple in nature but takes care of almost all the factors affecting the junction. Complete calculations regarding strength of connection of the specimen (SWSJWNR-01) of present study are presented as shown below:

- calculate the effective length of wall $\left(W_{\text {eff }}\right)$ :

$$
W_{\text {eff }}=3 t_{w}+t_{w}\left(\frac{1}{2}+\frac{1}{2^{2}}+\frac{1}{2^{3}}+\ldots\right)
$$

- calculate the critical shear stress $v_{c}$ from:

$$
v_{c}=\left(0.33 \sqrt{f_{c}^{\prime}}+v_{\text {add }}\right)-v_{g}
$$

- determine the value of factor $\alpha_{i}$ from:

$$
\alpha_{i}=1-\frac{1}{1+\frac{2}{3} \sqrt{\frac{W_{e f f}+d}{t_{w+d}}}}
$$

- calculate the value of $J_{c}$ from:

$$
\begin{aligned}
& J_{c}=\frac{d\left(W_{\text {eff }}+\frac{d}{2}\right)^{3}}{6}+\frac{\left(t_{w}+d\right) d^{3}}{12}+Y_{1}^{2}\left(t_{w}+d\right) d \\
& +2 Y_{2}^{2}\left(W_{\text {eff }}+\frac{d}{2}\right) d
\end{aligned}
$$

- calculate ultimate strength of the connection from:

$$
V_{u}=\frac{v_{c} b_{p} d}{\left(1+\alpha_{i} \frac{M}{V} \frac{Y_{1} b_{p} d}{J_{c}}\right)}
$$

where:

$W_{\text {eff }}$ is effective wall width;

$t_{w}$ is thickness of a planner shear wall;

$v_{c}$ is shear force transmitted through the compression zone of concrete;

$f_{c}$ is cylinder crushing strength of concrete;

$v_{\text {add }}$ is increase in the value of critical shear stress due to increase of ratio of flexural steel above $1 \%$;

$v_{g}$ is shear stress induced along critical section due to gravity load;

$\alpha_{i}$ is fraction of unbalanced moment transferred from slab to column by torsion and eccentricity of shear;

$d$ is effective depth of the slab;

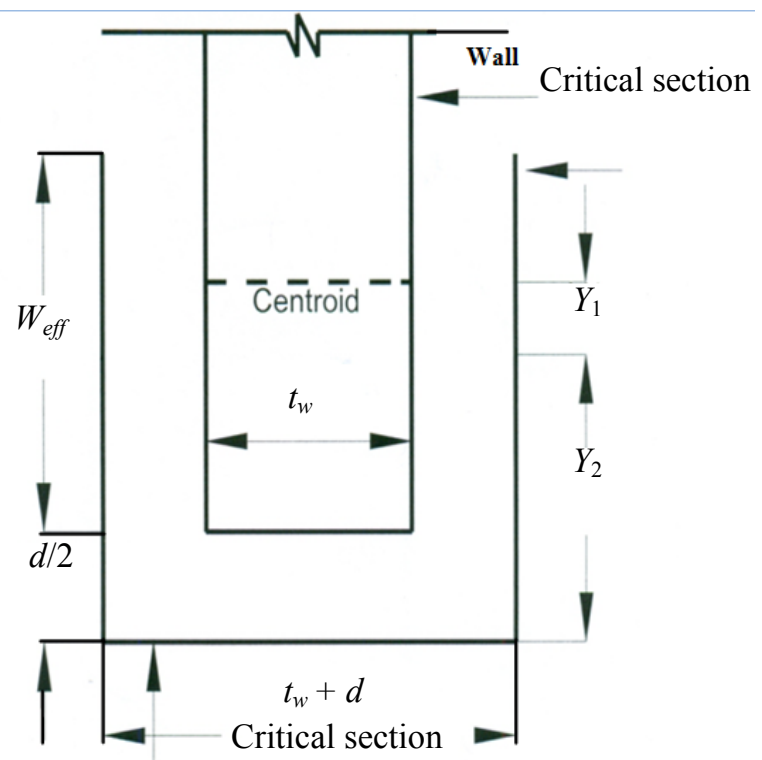

Fig. 6 Location of critical shear perimeter around the wall periphery proposed by Mahmood [1]. 
$J_{c}$ is a property of the critical perimeter analogous to polar moment of inertia;

$Y_{1}$ is distance from centriod to $Y_{2}$;

$Y_{2}$ is bay width $+3.5 t_{w}$;

$V_{u}$ is ultimate shear transfer capacity of a connection;

$b_{p}$ is the length of a perimeter at a distance $1.5 \mathrm{~h}$ from column face;

$M$ is moment;

$V$ is shear.

Using the above procedure, the ultimate loads/shear strengths of connection of all specimens were calculated adopting respective values of cylinder crushing strength and are given in Table 2.

\section{Materials}

\subsection{Concrete}

Concrete grade-30 with mean target compressive strength of $43 \mathrm{~N} / \mathrm{mm}^{2}$ on 28 days curing was used to cast all specimens. Because of the large quantity which was needed for every specimen, concrete was prepared in batches. Ordinary Portland cement with hill sand $10 \mathrm{~mm}$ uncrushed gravel was used for all concrete mixes. The fine aggregate passed through No. 16 sieve (ASTM (American Society for Testing and Materials)). Water/cement ratio was maintained at 0.47 and it was allowed to mix 5 min to prepare the concrete of required consistency. For determination of strength properties of hardened concrete, $100 \mathrm{~mm}$ cubes and $100 \times 200 \mathrm{~mm}$ cylinders were cast and cured with each specimen. All the cubes and cylinders were removed from the moulds 1 day after the casting. The compressive strength of concrete was taken as an average of three $100 \mathrm{~mm}$ specimens and the cylinder splitting tensile strength was taken as an average value of two $100 \times 200 \mathrm{~mm}$ cylinders. Two cylinders were used to determine the modulus of elasticity.

\subsection{Reinforcement}

\subsubsection{Flexural Reinforcement in Slab}

For the flexural design of the slab, the loads were selected after making sure that the failure of the slab itself would not occur. Accordingly, the slab was reinforced with $12 \mathrm{~mm}$ dia tor steel bars placed at distance of $115 \mathrm{~mm} \mathrm{c} / \mathrm{c}$ (center to center) in both directions. The shear strength of the slab was also calculated by following the codal provisions and this was found to be much higher than expected strength of the connection even when reinforced with the new form of vertical reinforcement. Only two layers of flexural steel bars were placed in the slab instead of four as in case of real buildings. Three samples of each type of steel bars were tested using Forney Universal Load Testing Machine and average yield and as well as ultimate strength.

\subsubsection{Wall Reinforcement}

Expectedly, the load at failure was to be higher than the specimens tested by previous investigators. Therefore, the wall was reinforced with eight $20 \mathrm{~mm}$ dia tor steel bars and $6 \mathrm{~mm}$ dia lateral ties were placed at average distance of $80 \mathrm{~mm} \mathrm{c} / \mathrm{c}$. Fig. 7 shows complete arrangement of reinforcement of the specimens.

\subsubsection{New Form of Shear Reinforcement}

New form of shear reinforcement was used at the critical section around the wall periphery in each specimen with different locations and number of piece. Fig. 8 shows the placement and quantity of $12 \mathrm{~mm}$ wide pieces of I-section for specimens No. SWSJWNR-06.

Table 2 Design load of the specimen.

\begin{tabular}{lllll}
\hline Model No. & No. of I-section & Location of I-section & Cylinder crushing strength & Design ultimate load $V_{u}(\mathrm{kN})$ \\
\hline SWSJWNR-01 & - & - & 33.50 & 40.80 \\
SWSJWNR-02 & 11 & $0.5 d$ & 31.97 & 39.80 \\
SWSJWNR-03 & 14 & $0.5 d$ & 31.72 & 39.70 \\
SWSJWNR-04 & 14 & $0.65 d$ & 32.48 & 43.40 \\
SWSJWNR-05 & 14 & $d$ & 33.97 & 52.50 \\
SWSJWNR-06 & 17 & $d$ & 33.82 & 52.40 \\
\hline
\end{tabular}



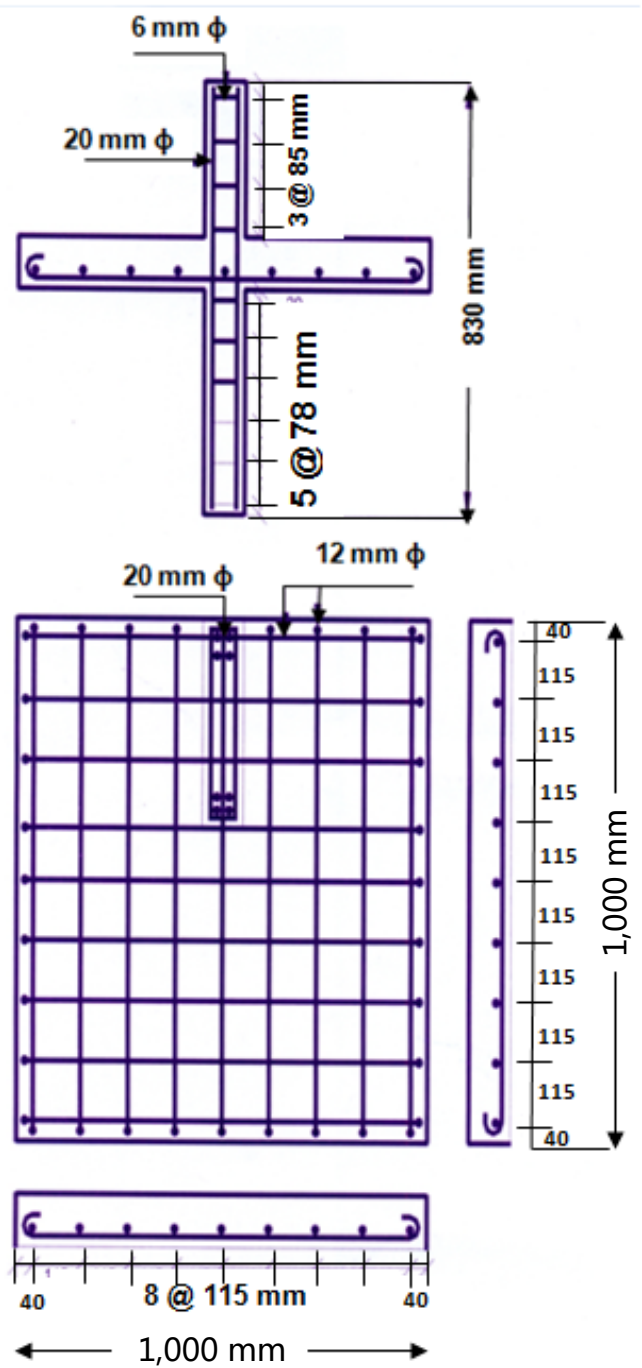

Fig. 7 Arrangement of reinforcement of the specimens.

Three pieces of this I-section were welded with two steel bars pieces as shown in Fig. 9, and were tested by using ULTM (Universal Load Testing Machine) to determine experimentally yield strength of this new form of reinforcement. The results of this test are presented in Table 3.

\section{Experimental Setup}

\subsection{Supporting Arrangement}

Since, for the sake of economy, no base slab was cast, the specimen had to be positioned up-rightly at a proper location and held firmly to avoid rigid body
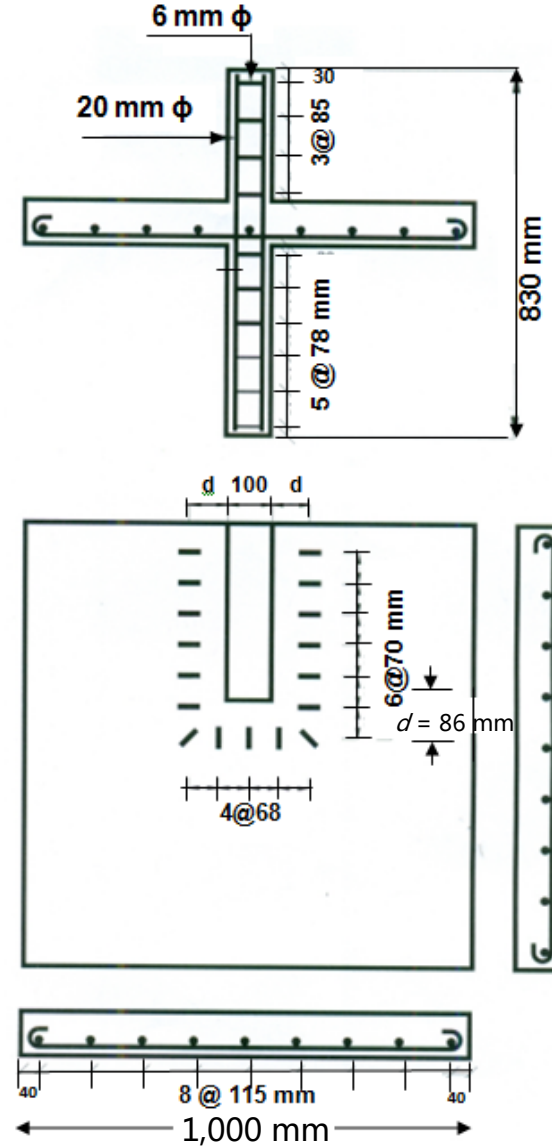

Fig. 8 Arrangement of reinforcement and location of I-section of the specimens SWSJWNR-06.

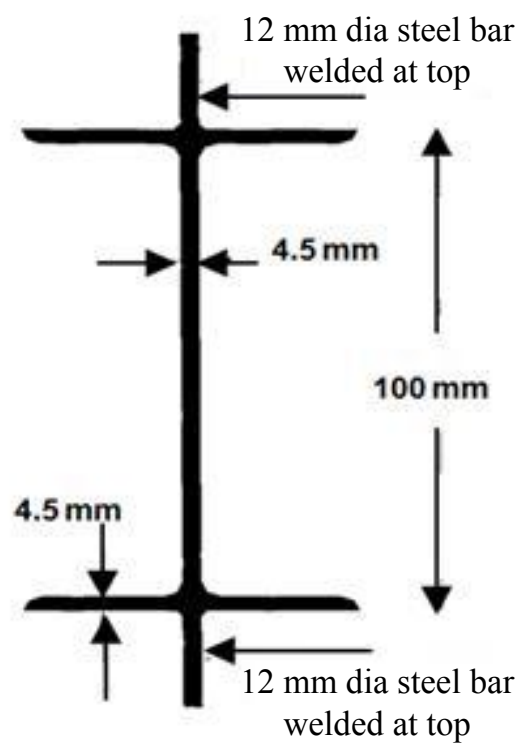

Fig. 9 Pieces of I-section tested by universal testing machine. 
Table 3 Yield stress and modulus of elasticity of I-section.

\begin{tabular}{llllll}
\hline Serial No. & $\begin{array}{l}\text { Yield stress } \\
\left(\mathrm{N} / \mathrm{mm}^{2}\right)\end{array}$ & $\begin{array}{l}\text { Ultimate stress } \\
\left(\mathrm{N} / \mathrm{mm}^{2}\right)\end{array}$ & Yield strain & $\begin{array}{l}\text { Modulus of elasticity } \\
\left(\mathrm{kN} / \mathrm{mm}^{2}\right)\end{array}$ & Percentage of elongation \\
\hline 01 & 456.50 & 695.32 & 0.002000 & 228.25 & 7.98 \\
02 & 412.55 & 711.12 & 0.001500 & 275.03 & 5.35 \\
03 & 447.95 & 581.19 & 0.001500 & 286.92 & 2.67 \\
\hline Average & 439.00 & 662.50 & 0.001666 & 263.40 & 5.32 \\
\hline
\end{tabular}

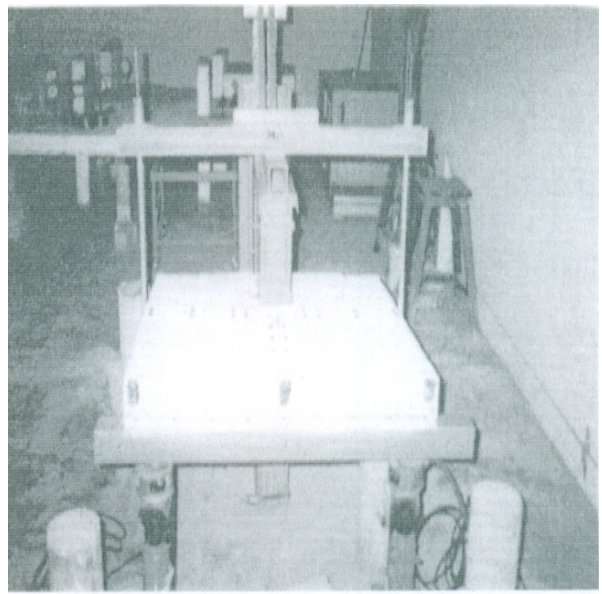

Fig. 10 Pictorial view of testing.

rotation of specimen itself about its own wall edge and consequently creating stress concentration in these regions of wall leading to premature failure due to damage to the wall before reaching the ultimate failure load of the wall-slab connection as desired. Based on the experience of first loading cycle of first specimen, it was deemed essential to strengthen the wall externally by providing confinement with the help of steel plates on all the four sides of the walls. Photograph presented in Fig. 10 shows the pictorial view of testing arrangement and supporting arrangement used during this study while dimensioned details are shown in Fig. 11.

\subsection{Testing Arrangement}

Since the effect of lateral load was to be simulated by the uniform displacement of the line of contra flexure, a hollow square steel section got fabricated by welding $100 \times 100 \mathrm{~mm}$ rolled steel angle sections all the way through along their length. Two loading points were identified and $100 \mathrm{~mm}$ thick plate was welded there to avoid the local deformation because of concentration of load. Two manually operated hydraulic jacks each of $10 \mathrm{t}$ capacity with a maximum extension of $140 \mathrm{~mm}$ were used for applying the load. Since, in the laboratory, there was no reaction floor hence beneath the jacks the ground was strengthened by constructing special foundation of RCC with only thin layer of concrete and plastered with thin coat of cement mortar, the possibility of sinking of the jacks in to the floor under load could be avoided. Although the uniform displacement of the line of contra flexure was achieved, for the sake of convenience, instead of imposing equal increment of displacements, the equal increments of load were applied gradually. Dial gauges as well as transducers were used to measure the displacement at the central point of the loading beam of each specimen.

\subsection{Displacement Measurement}

An electrical displacement transducer was used to record displacement. The transducer was installed at proper position with the help of an adjustable steel stand and it was connected to an electronic display system, which exhibited displacement in $\mathrm{mm}$ to an accuracy of $0.01 \mathrm{~mm}$. Three dial-gauges in front, one at the back of the wall and two at the remote corners, were also placed. The dial gauges at the back of the wall were particularly used to measure the rigid body rotation.

\subsection{Load Measurement}

Two load cells of $100 \mathrm{kN}$ capacity each coupled with load cell amplifiers previously calibrated with the help of universal load testing machine were used during this study. The LCA (life cycle assessment) display values in DVM (digital voltmeter) units, which are then converted into $\mathrm{kN}$ from the calibration chart. 

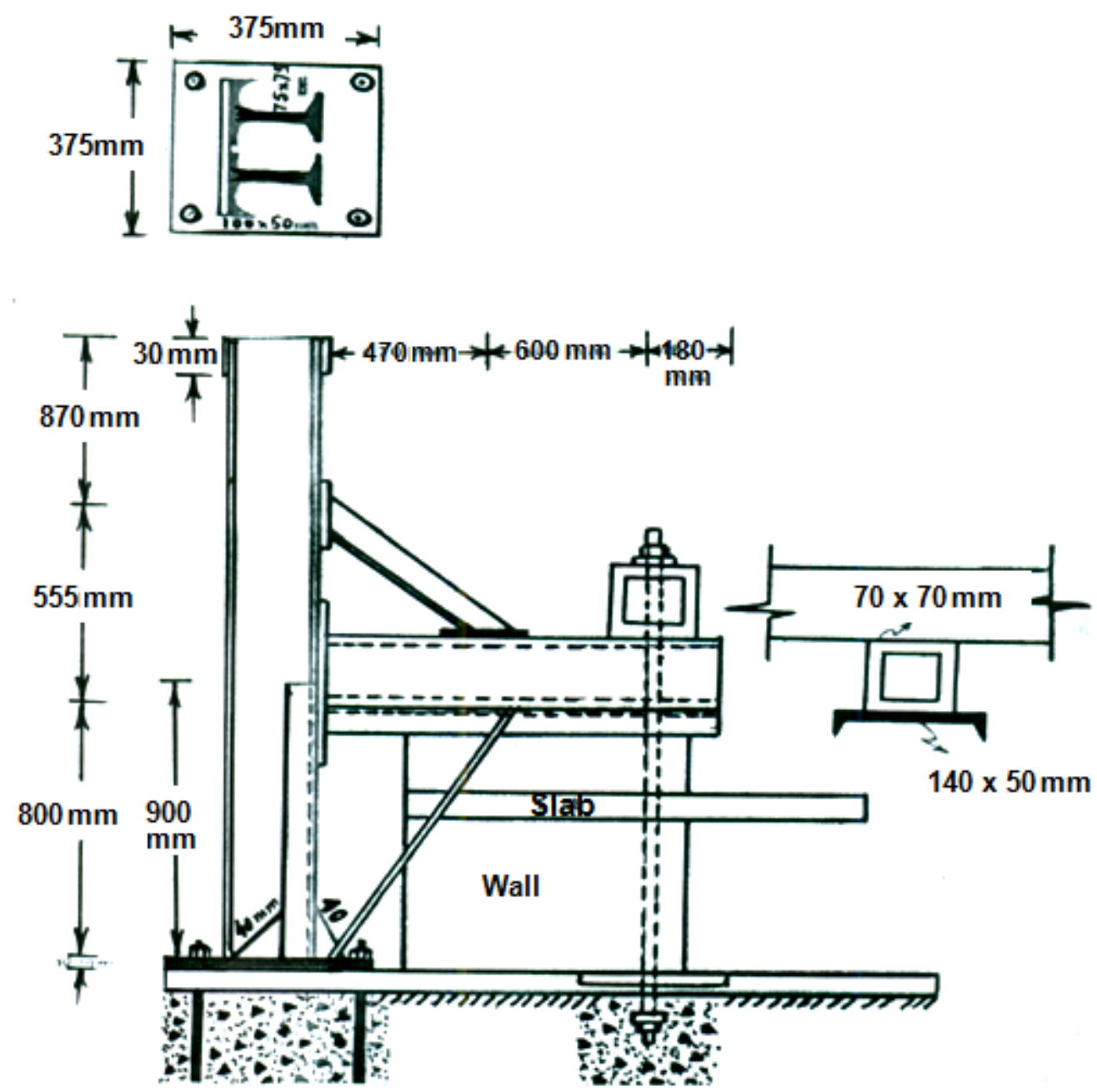

Fig. 11 Dimensional details of supporting arrangement.

\subsection{Strain Measurement}

Demec pads were stuck in pairs across the transverse critical section and perpendicular to it and the central location. The strain was measured with demec gauge with an accuracy of 20 micro strains per sub-division. Demec pads used were circular in shape with $10 \mathrm{~mm}$ in diameter and $10 \mathrm{~mm}$ thick. For fixing the demec pads, the concrete surface was first cleaned and made smooth by grinding using a grinding stone and then by fine sandpaper. Carbon tetrachloride was used to remove the dirt and grease. Epoxy cement adhesive (Drug A) and hardener (Drug B) mixture were applied to the cleaned surface and demec pads were stuck on it by firmly pressing with thumb for about 2 min.

\section{Test Procedure}

Initially, $5 \%$ of estimated ultimate load was applied for a short time period and the specimen was unloaded. Readings were taken of all the dial-gauges, transducer, load cell and strain for each of the specimens with no load before starting the actual test. Care was taken to see that the applied load was not causing any eccentricity and consequent twisting of the specimen. To allow for the overall deformation, creep, etc., the readings were taken $5 \mathrm{~min}$ after application of each load increment and the possibility of crack formation if any was observed. If there were any cracks formed, they were marked with a line and numbered at the tip by drawing a short cross line. The total time for each test was in the range of $4 \mathrm{~h}$ to $6 \mathrm{~h}$. The strength 
properties of the concrete were obtained by testing the cubes and cylinders on the day of testing each model.

\section{Behavior of Specimens}

\subsection{Specimen SWSJWNR-01 (without New Form of Shear Reinforcement)}

For the first time, a hair-crack visible by naked eye appeared at a load, which was $50 \%$ of ultimate load, the location of this crack is shown in Fig. 12a. As the loading progressed this crack widened and more crack developed as shown in Fig. 12b. At about 80\%, load cracking looks like that in Fig. 12c. The cracking pattern just before failure is shown in Fig. 12d. Clearly, this was a case of junction failure. It can be observed from Fig. 12d that the wall punched through the slab. The failure was sudden, brittle and without impending warning. The failure occurred at the load of $44.1 \mathrm{kN}$.

\subsection{Specimen SWSJWNR-02}

Eleven I-section pieces are used as a new form of shear reinforcement at the critical section around the wall periphery at a distance of $0.5 d$ from the sides of wall, where $d$ is effective depth of slab. The shear reinforcement used was $0.74 \%$ of the critical area around the wall periphery. The cracking appeared at $40 \%$ of the ultimate load. The cracking progressed as the load increased. Several cracks appeared when the load reached $70 \%$ of ultimate load. The cracks were extended and widened when the load reached at $80 \%$ of ultimate load. Clearly, this was also the shear failure due to punching of wall through the slab. The failure occurred at a load of $53.04 \mathrm{kN}$.

\subsection{Specimen SWSJWNR-03}

Obviously, it was expected that the load bearing capacity of this specimen in terms of strength of junction would be higher than the previous specimen due to increase of quantity of I-section pieces as 14 at the same location at $0.5 \mathrm{~d}$. This new form of shear reinforcement was $0.94 \%$ of the critical area around the wall periphery. The ultimate load increased by only $7.7 \%$ than the previous. However, as expected, the crack pattern and mode of failure resembled with the previous specimens. For the first time, hair crack visible by naked eye at the bottom of the slab appeared at $37 \%$ of ultimate load. Some more cracks appeared when the load reached at the $50 \%$ of ultimate load. Several cracks at the top and bottom developed at $82 \%$ of ultimate load. This was also the case of junction failure. The load at failure was $57.12 \mathrm{kN}$.

\subsection{Specimens SWSJWNR-04}

Same quantity of new form of shear reinforcement (I-section) as that in the previous specimen (i.e., 14) was provided. This time the location of this reinforcement was changed to $0.65 d$. This caused the increase of the area around the wall periphery. Consequently, the ratio of shear reinforcement decreased to $0.88 \%$ of that of previous specimen. The



(a)

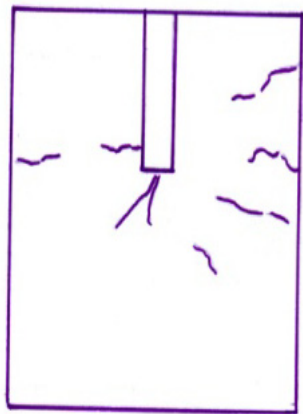

(b)

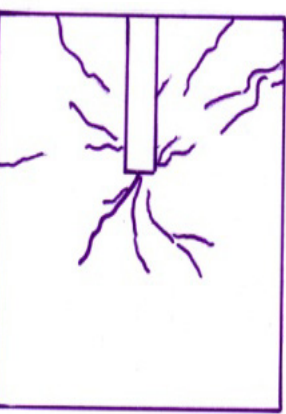

(c)

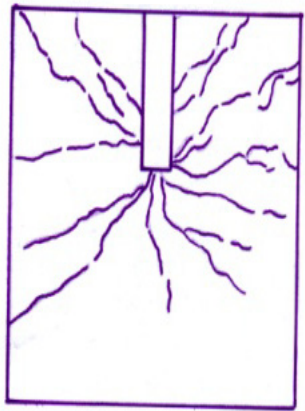

(d)

Fig. 12 Crack pattern of the slab: (a) at $50 \%$ of ultimate load; (b) at $70 \%$ of ultimate load; (c) at $80 \%$ of ultimate load; (d) at the load just before failure of model SWSJWNR-01. 

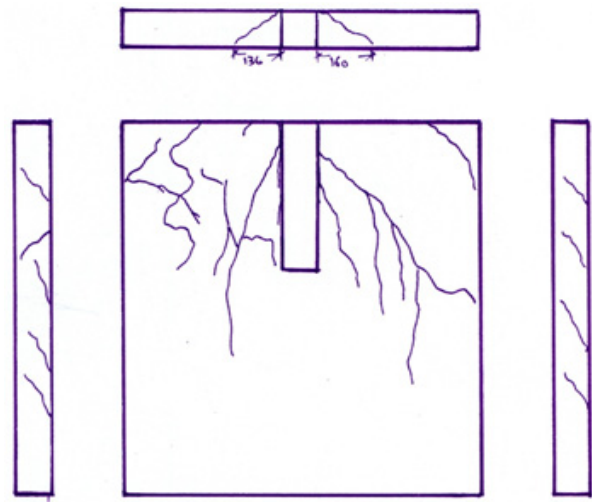

Top

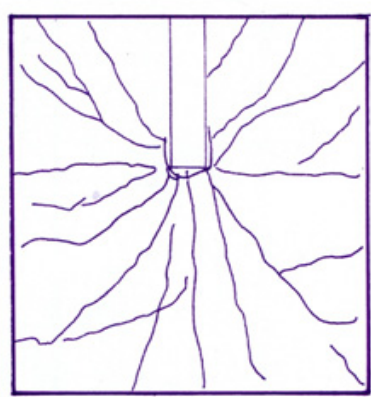

Bottom

Fig. 13 Crack pattern of the slab at top and bottom with sides and back of the model SWSJWNR-05.

cracks just started at the bottom of the slab at $48 \%$ of ultimate load. However, as expected, the mode of failure resembled with those of the previous specimens but cracking at the bottom showed different pattern. Several cracks radiated in various direction from the inner face of the wall. However, the specimen behaved more or less like previous specimen. This was also the case of junction failure. The load at failure was $63.6 \mathrm{kN}$.

\subsection{Specimen SWSJWNR-05}

This specimen was tested by maintaining the same quantity of I-section piece as in specimen SWSJWNR-04 (i.e., 14) at wider location up to $d$, where $d$ is effective depth of slab.

The load at failure showed nominal improvement due to change of location. The cracking of this specimen at the bottom was more or less similar to that of specimen SWSJWNR-04. Cracking started at $55 \%$ of ultimate load. Several cracks appeared at the top and the bottom of the slab at $80 \%$ of ultimate load. Fig. 13 shows the crack pattern of the specimen. The load at failure was $67.32 \mathrm{kN}$.

\subsection{Specimen SWSJWNR-06}

Increasing the quantity of new form of reinforcement up to 17 pieces of I-sections at same location (i.e., $d$ ) as it was in specimen SWSJWNR-05, the 6th specimen was cast and tested. The mode of failure did not show much improvement with the increase of the quantity of this reinforcement which is $0.97 \%$ of the critical area around the wall periphery. The cracking of this specimen at the bottom was approximately similar to that of specimen SWSJWNR-05. The load at failure was $69.63 \mathrm{kN}$.

\section{Discussion of Results}

The most important observation regarding the behavior of specimens is the crack causing failure of the specimens. It appears from the experimental evidence of this study that critical shear perimeter shifts away from the sides of wall due to shifting of location of I-section piece used as new form of shear reinforcement although the mode of failure was the same, i.e., punching of wall through the slab which is the case of junction failure. Based on the test results, it can be deduced that the shift of the critical perimeters should be taken into consideration because this would give better estimation of the strength of wall-slab junction in case of new form of shear reinforcement. It is therefore recommended that the new location of critical shear perimeter be taken at a distance of $0.75 d$ instead of $0.5 d$. Hence, the estimation of wall-slab junction of laterally loaded shear wall building should be based on $0.75 d$ instead of $0.5 d$, when this type of new form of shear reinforcement is used. Fig. 14 shows a comparison of the load-displacement relationship of all the test specimens. It is apparent from the figure that ultimate load as well as the displacement increase as the ratio of new shear reinforcement increases. The deformation becomes 




Fig. 14 Load-displacement relationship of all the models, i.e., SWSJWNR-01 to SWSJWNR-06.

even more than $60 \%$ of the thickness of the slab itself at failure of specimen SWSJWNR-06, containing maximum shear reinforcement. Clearly, this indicates that there would be excessive deflection of the slab in real structures giving a warning that the failure would be imminent. Since the junction failures both in case of flat slabs and coupling slabs are sudden and brittle, this excessive deflections before failure is a positive point. Increasing of shear reinforcement in specimens showed further shifting of shear perimeter to a distance of $d$.

However, from the test results which include crack pattern, mode of failure, location of cracks causing failure in the slab and their locations, it is suggested that the critical perimeter for junction failure around the wall periphery preferably be assumed to be at a distance of $0.75 d$ instead of $d / 2$. It may be mentioned here that, for slabs, the location of the critical shear perimeter is assumed to be at a distance of $d / 2$ by ACI-318 and $1.5 h$ by CP8110. Based on the results, the method to estimate the strength of wall-slab junction originally proposed by Mahmood [1] has been modified to take into account the additional component of strength imparted by this new form of shear reinforcement. Here as expected, strain is quite considerable when no new form of shear reinforcement is added. Nevertheless, it decreases to its lowest value when the ratio of this special shear reinforcement is $0.88 \%$. Obviously, this is due to the fact that bulk of stresses is born by the new form of shear reinforcement. Similarly, situation is encountered in case of compressive strain measured at various other locations in the slab. It is obvious that in all the specimens the strain is the lowest in the slab along the critical section at the central point near the inner face of the wall. Several other investigators have already reported this fact. The value is highest at second points from central locations.

\section{Analysis of Results}

The last column of Table 4 shows the average crack 
Table 4 Comprehensive table showing all values of loads with an average crack location of the specimens.

\begin{tabular}{lllllllc}
\hline Specimen No. & \multirow{2}{*}{ No. of I-section } & $\begin{array}{l}\text { Experimental } \\
\text { ultimate load }\end{array}$ & $\begin{array}{l}\text { Design load } \\
(\mathrm{N})\end{array}$ & $\begin{array}{l}\text { Percentage } \\
\text { difference }\end{array}$ & $\begin{array}{l}\text { Revised design } \\
\text { load (N) }\end{array}$ & $\begin{array}{l}\text { Percentage } \\
\text { difference }\end{array}$ & $\begin{array}{l}\text { Average crack } \\
\text { location }(\mathrm{mm})\end{array}$ \\
\hline SWSJWNR-01 & Nil & 44.10 & 40.8 & 8.1 & 39.9 & 10.5 & 79 \\
SWSJWNR-02 & 11 & 53.90 & 39.8 & 35.4 & 42.8 & 25.9 & 110 \\
SWSJWNR-03 & 14 & 57.10 & 39.7 & 43.8 & 45.4 & 25.8 & 132 \\
SWSJWNR-04 & 14 & 63.64 & 43.4 & 46.6 & 48.1 & 32.3 & 148 \\
SWSJWNR-05 & 14 & 67.32 & 52.5 & 28.2 & 41.9 & 60.7 & 146 \\
SWSJWNR-06 & 17 & 69.36 & 52.4 & 32.4 & 48.0 & 44.5 & 140 \\
\hline
\end{tabular}

Table 5 Percentage increase of experimental ultimate load.

\begin{tabular}{lllll}
\hline Specimen No. & No. of I-section & Location of I-section & $\begin{array}{l}\text { Experimental ultimate load } \\
(\mathrm{N})\end{array}$ & $\begin{array}{l}\text { Ratio of ultimate load with } \\
\text { respect to Specimen 01 }\end{array}$ \\
\hline SWSJWNR-01 & Nil & Nil & 44.1 & - \\
SWSJWNR-02 & 11 & $0.5 d$ & 53.90 & 1.22 \\
SWSJWNR-03 & 14 & $0.5 d$ & 57.10 & 1.30 \\
SWSJWNR-04 & 14 & $0.65 d$ & 63.64 & 1.44 \\
SWSJWNR-05 & 14 & $d$ & 67.32 & 1.52 \\
SWSJWNR-06 & 17 & $d$ & 69.36 & 1.57 \\
\hline
\end{tabular}

location in millimeters from the side of the wall. During experimental study, it was observed that the shear crack causing the failure of first specimen was averagely $79 \mathrm{~mm}$ away from the side of the wall. However, this distance increased in the subsequent specimen as the new form of shear reinforcement consisting of pieces of I-section was placed and increased in the subsequent specimens. From Table 4, it can be observed that the change of location of I-section pieces was also changed from $0.5 d$ to $0.65 d$ and finally to $d$. This seems to have affected the location of cracks, which increase to a maximum value of $148 \mathrm{~mm}$ in case of specimen SWSJWNR-04. Based on the results of this experimental work, it is suggested that this type of shear reinforcement be provided at distance of $0.75 d$ from the wall. Table 4 gives the details of experimental ultimate design loads, the initial design loads, the revised design load and the percentage difference for all the specimens. In all the cases, it can be observed that the experimental load is substantially higher than even the revised design loads, a maximum difference of $60.7 \%$ is reached in the case of specimen SWSJWNR-05. In Table 5, there is a maximum increase of the load (with respect to specimen SWSJWNR-01 without shear reinforcement) of 1.57 times in case of specimen SWSJWNR-06.
From this study, it can be inferred that failure was governed by the strength of concrete and the steel could play only limited role rather than controlling the failure of the junction. The increase of I-section pieces from specimens SWSJWNR-05 to SWSJWNR-06 caused only a marginal increase of approximately 1.05 times of the ultimate load. Therefore, further increase of this type of reinforcement may not be useful. The ratio of shear reinforcement as percentage of the area of critical shear perimeter is only $0.97 \%$. It is therefore recommended that the placement of this type of reinforcement must not be beyond $1 \%$. However, when the location of critical shear perimeter is assumed to be at a location of $0.75 d$ instead of $0.5 d$, the estimated strength as predicted by Memon and Narwani's method [5] will also be enhanced due to increase area. But substantial factor of safety would still exist.

\section{Conclusions}

By using the new forms of shear reinforcement, the ultimate loads of specimens were increased by up to 1.57 times compared to that of the control specimen. However, for the design purpose, the increase in the ultimate load is limited to 1.50 times when new shear reinforcement is provided to an extent of $1 \%$. 
A ratio of $0.88 \%$ of critical section for shear along the wall periphery has been found to be optimum.

This new form of shear reinforcement should be placed at a distance of $0.75 d$ instead of $0.5 d$, where $d$ is effective depth of the slab.

The use of the new method of the shear reinforced has shown a relatively ductile failure of the test specimen. At failure, the ratio of deflection of specimen to the slab thickness for the specimen SWSJWNR-06 was approximately twice, $60 \%$, compared to that for the control specimen SWSJWNR-01.

Although the new form of shear reinforcement shows a significant increase in the ultimate load of wall-slab junction up to $57 \%$, the full strength of steel shear reinforcement is not utilized.

A revised method of providing the shear reinforcement has been proposed by suggesting amendments in the method developed by Memon and Narwani [5].

The ultimate loads of the specimens given by the new method and those observed in the tests were in reasonable agreement.

\section{Significance of Research}

Wall-slab junction is highly sensitive area of tall shear wall buildings where high concentration of stresses due to bending, shear and torsion are caused by lateral and gravity forces. This can lead to a premature failure of tall shear wall buildings. Although a significant amount of work has been carried out in the area under research, more work is required in order to develop a definite design procedure with more convenient and economical type of shear/torsion reinforcement in terms of ratio vs. economy. This aspect is under taken as part of research program, the details of which are presented in this paper.

\section{Acknowledgments}

The experimental work was carried out in the Structures Laboratory of the Department of Civil
Engineering at Quaid-e-Awam University of Engineering Science and Technology, Nawabshah (Sindh), Pakistan. The authors acknowledge the support and assistance provided by the university.

\section{References}

[1] Mahmood, M. 1984. "Strength and Stiffness of Shear Wall Floor Slab Connections.” Ph.D. thesis, University of Glasgow.

[2] Bari, M. S. 1987. "Design of Shear Wall-Slab Connection Using Shear Reinforcement.” Ph.D. thesis, University of Glasgow.

[3] Noor, A. M. 2003. "Strength of Steel Fibre Reinforced Concrete Shear Wall-Floor Slab Junction.” M.Phil thesis, Mehran University of Engineering \& Technology.

[4] Hossain, K. M. 2003. "Nonlinear Performance of Slabs in Coupled Shear Wall Structures.” Advances in Structural Engineering 6 (4): 339-52.

[5] Memon, M., and Narwani, T. D. 2008. "Experimental Investigations Regarding Behaviour of Tall Buildings Subjected to Lateral Loading.” Journal of Quality and Technology Management 4 (1): 39-50.

[6] Rajkumar, R. V., Greeshma, S., and Jaya, K. P. 2009. "Parametric Investigation of Shear Wall-Floor Slab Connection." In Proceedings of National Seminar on Performance of Disaster Resistant Structures, 35-42.

[7] Greeshma, S., and Jaya, K. P. 2011. "Effect of Slab Shear reinforcement on the Performance of Shear wall-Floor Slab Connection.” ASCE (American Society of Civil Engineers) Journal of Performance and Constructed Facilitie 27 (4): 391-401.

[8] Wolanski, A. J. 2004. "Flexural Behavior of Reinforced and Pre-stressed Concrete Beams Using Finite Element Analysis.” M.Sc. thesis, Marquette University.

[9] Elnounu, G. F. R. G. 1985. "Design of Shear Wall Connections.” Ph.D. thesis, University of Glasgow.

[10] Dilger, W., Elmasri, M. Z., and Gali, A. 1978. "Flat Plats with Special Reinforcement Subject to Static Dynamics Moment Transfer." Journal of American Concrete Institute (75-56): 543-75.

[11] Hago, A. W. 1982. "Direct Design of Reinforced Concrete Slab.” Ph.D. thesis, University of Glasgow.

[12] Muhammad, A. M. 1995. "Flexural Behaviour of Reinforced Concrete Coupling Slab in Shear Wall Structures Subjected to Lateral Loads.” M.Phil thesis, Mehran University of Engineering and Technology.

[13] Wood, R. H. 1968. "The Reinforcement of Slab in Accordance with a Predetermined Field of Moment.” Concrete 2 (2): 319-20.

[14] Armer, G. S. T. 1968. "Contribution to Discussion on Ref. 34.” Concrete 2 (8): 319-20. 